\title{
Prevalence of Beta-hemolytic Streptococcus Carrier State and its Sensitivity to Different Antibiotics among Guidance - School Children in Kerman-Iran
}

\author{
Fatemeh Nabipour and Mohammadali Tayarzadeh \\ Department of Pathology, Medical School, Kerman Medical Sciences University \\ Emam highway, Kerman, Iran
}

\begin{abstract}
Group A $\beta$-hemolytic streptococcus is the most frequently isolated pathogen in acute pharyngitis and pharingotonsilits Cases in school - aged children. Resulting in dangerous complications such as rheumatic fever and glomerulonephritis, diagnosis and treatment of the disease would be of great importance. The aim of this study was determination of the frequency of group A $\beta$ hemolytic streptococcus carriers in middle school in Kerman. A total of 200 students with ages ranging from 11 to 15 years were included in the study. The inclusion criteria were having no symptoms or signs of upper respiratory tract infection, and no antibiotics usage in the last two weeks. The overall prevalence of group A $\beta$-hemolytic streptococcus carrier state in all age groups was $28.5 \%$. After doing antibiogram test, all of them were sensitive to vancomycin, erythromycin and cephalotin and reversely resistant to penicillin. Our study suggests that inappropriate use of these antibiotics increases the chronic carrier state of Group A $\beta$-hemolytic streptococcus in our community.
\end{abstract}

Key words: Group A $\beta$-hemolytic streptococcus, Carrier, Antibiogram, Kerman

\section{INTRODUCTION}

Sore throat caused by group A beta-hemolytic streptococcus is one of the most common diseases during adolescence and early adulthood which makes a lot of problems and consumes a great budget for its treatment and complications, all over the world ${ }^{[1-4]}$. Beta-hemolytic streptococcus infection leads to serious complications as rheumatic fever and acute glomerulonephritis. According to studies on streptococcal pharyngitis complications, adequate antibiotic therapy has declined the incidence of rheumatic fever about ten times ${ }^{[5,6]}$.

Of commonly used antibiotics for the treatment of beta-hemolytic streptococcus infection are penicillin and its family (including ampicillin).As proper usage of antibiotics leads to rapid treatment of streptococcal infection, inadequate treatment and changing in bacterial characteristics leads to bacterial resistance to antibiotics ${ }^{[7,8]}$. This results in unsuccessful treatment and increased complications. On the other hand healthy carrier state with resistance to common antibiotics would be more prevalent. These days pharyngeal bacterial culture is a common and efficient method for the diagnosis of group A beta-hemolytic streptococcus.

In this method pharyngeal bacteria are transferred to a suitable culture media and then if group A betahemolytic streptococcus grows sensitivity test to antibiotics (antibiogram)will be performed.

Making an epidemiological model regarding bacterial resistance and improving practitioners' knowledge about bacterial resistance to commonly used drugs is of great importance.

In this cross sectional study, the prevalence of group, A beta-hemolytic streptococcus healthy carrier state among 11-15 year old individuals was comprehensively studied for the first time in Iran.

\section{MATERIALS AND METHODS}

In a cross sectional descriptive study 200 middle school students in Kerman (including male and female) were studied. To calculate the sample size, prevalence of healthy carrier state was regarded $15-20 \%$.

Sampling method was regular multistage cluster sampling. Twenty middle schools (10 for girls and 10 for boys) were selected randomly from the list of schools in Kerman education administrations No. 1 \&2 (from each of them 10 schools were selected). Then 10 classes were selected randomly from each school and subsequently the tenth student of each class was selected if meeting the inclusion criteria.

* No history of tonsillectomy.

* Absence of signs or symptoms showing upper respiratory infection.

* No antibiotic usage during the last two weeks before sampling.

After determining the students who met these criteria and getting permission from their parents, personal profile including parents' profession, number of family members and parents' educational level were recorded in special data gathering forms. Then the 
studied students were prepared for sampling from pharynx.

To get a sample, a sterile swab was rubbed on tonsils, tongue, oral walls and posterior pharyngeal wall. In order to avoid bacterial death, "Cary Blair" media was applied and samples were transferred to lab in less than one hour. "Base blood agar" culture media was used to distinguish and separate group A betahemolytic streptococcus. Medias were stored in refrigerator and used in a maximum of one week length. To separate staphylococcus areus from group A betahemolytic streptococcus, "manitol salt agar" media was applied. After the culture process was performed, plated were placed in a 37-degree (centigrade) incubator within a jar which contained $10 \% \mathrm{Co} 2$, for 24-48 hours.

To recognize group A beta-hemolytic streptococcus, solitary colonies were assessed by means of focused light. Small colonies with a bright circle around, which meant $\beta$-hemolysis were selected and gram-staining was performed. Catalase test was done to distinguish streptococcus from staphylococcus. Bacteria which had a negative catalase test were assessed by sensitivity test using bacitracin and incubated in a jar for 24 hours in 37 degrees centigrade.

After this period of time, any bacteria which showed sensitivity to bacitracin and had a bright circle around was mentioned as group A beta-hemolytic streptococcus $^{[9-13]}$.

After diagnosis of group A beta-hemolytic streptococcus was made, antibiogram test was done using cephalothin, erythromycin, tobramycin, tetracycline, ampicillin, amoxicillin, Co-tromoxazole, vancomycin, cloxacillin, gentamicin and penicillin (all from padtan teb corporation). Diameter of the bright circle around antibiotic disk was was measured by a ruler and according to the standard table; bacteria were classified as sensitive, semi- sensitive and resistant.

After data was gathered, it was analyzed by means of SPSS 9.05 software. ANOVA and Paired t-test were used and the level of significance was determined as $\mathrm{P}<0.05$.

\section{RESULTS}

From 200 students which were studied, 100 were male and 100 female. $97 \%$ of students were $11-15$ years old and the mean age was $13+/-1.24$ (Mean+/-SD).Age distribution of streptococcus carrier students is presented in Table 1. Distribution of carrier frequency regarding the number of family members was also studied. In this study, mean family member frequency was $6.39+/$ - 1.97 (Mean+/-SD).streptococcus carriers were mostly seen in eight-person and also more crowded families.

After studying the cultured samples, 57 students (28.5\%) were group A beta-hemolytic streptococcus carriers which in this group 31 (54.4\%) were male and $26(45.5 \%)$ were female.

Regarding the students' fathers' job, carrier students were most frequently found among students with retired, jobless or dead fathers (32\%).

According to their fathers' level of education, mostly carriers were seen among students with illiterate fathers. Also regarding the students' mothers' job, carrier state was very common among students whose mothers were house-wives (28\%).

In antibiogram test which was performed on group A beta-hemolytic streptococcus carriers (57 students), mean bright circle diameter around each antibiotic disk was measured (Table 2).

This way the proportion of sensitivity was highest for vancomycin $(89.5 \%)$. Cephalotin and erythromycin were in the second position (59.5\% sensitivity). Surprisingly all group A beta-hemolytic streptococci which were cultured, were resistant to penicillin, as the most reliable and commonly used drug.

After penicillin, the highest proportion of resistance was due to co-trimoxazole (91.2\%) and amoxicillin $(87.7 \%)$. Non of the isolated streptococci were sensitive to ampicillin. These were all resistant or semi sensitive (Table 3).

Another point in this study was the frequency of some other bacteria in the prepared samples.

Non pneumococcal $\alpha$-hemolytic streptococcus was detected in 196 students (98\%) while beta-hemolytic streptococci from groups other than A, were seen in 36 students(18\%)and coagulase positive and negative staphylococci were detected respectively in $23(11.2 \%)$ and $17(8.5 \%)$ of students.

Table 1: Frequency of group A beta-hemolytic streptococcus carrier state, by age among middle school students- Kerman

\begin{tabular}{lccc}
\hline Age (year) & Number of studied cases & Number of carriers & Percentage of carriers \\
\hline 11 & 14 & 3 & 21 \\
12 & 65 & 20 & 30 \\
13 & 59 & 14 & 23 \\
14 & 38 & 12 & 33 \\
15 & 17 & 6 & 35 \\
16 & 5 & 1 & 20 \\
17 & 2 & 1 & 50 \\
\hline
\end{tabular}


Table 2: Mean bright circle diameter from antibiogram tests performed in group A beta-hemolytic streptococcus carriers by sort of antibioticmiddle school students of Kerman

\begin{tabular}{lllll}
\hline Antibiotic & $\begin{array}{l}\text { Range of } \\
\text { sensitivity }\end{array}$ & $\begin{array}{l}\text { Range of } \\
\text { Semi-sensitivity }\end{array}$ & $\begin{array}{l}\text { Range of } \\
\text { Resistance }\end{array}$ & $\begin{array}{l}\text { Mean bright } \\
\text { circle diameter }\end{array}$ \\
\hline Cephalothin (CF) & $>18$ & $15-17$ & $<14$ & $18.05 \pm 5.58$ \\
Erythromycin (E) & $>18$ & $14-17$ & $<13$ & $19.93 \pm 5.39$ \\
Tobramycin (T) & $>15$ & $13-14$ & $<12$ & $12.39 \pm 4.1$ \\
Tetracycline (Te) & $>19$ & $15-18$ & $<14$ & $16.23 \pm 6.40$ \\
Ampicillin (Am) & $>29$ & $21-28$ & $<20$ & $15.30 \pm 5.17$ \\
Amoxicillin (Amx) & $>14$ & $12-13$ & $<11$ & $8.32 \pm 2.78$ \\
Co-trimoxazole & $>15$ & $12-15$ & $<12$ & $8.65 \pm 3.24$ \\
(S\&T) & & & \\
Vancomycin (Va) & $>12$ & $10-11$ & $<9$ & $16.02 \pm 3.83$ \\
Cloxacillin (Cx) & $>14$ & $10-13$ & $<9$ & $12.82 \pm 3.04$ \\
Gentamicin (Gm) & $>15$ & $13-14$ & $<12$ & $11.14 \pm 4.39$ \\
Kanamycin (K) & $>18$ & $14-17$ & $<13$ & $7.68 \pm 1.77$ \\
Penicillin (P) & $>29$ & $21-28$ & $<20$ & \\
\hline
\end{tabular}

Table 3: Group A beta-hemolytic streptococcus sensitivity to different antibiotics in carriers among middle school students-Kerman

\begin{tabular}{llll}
\hline Antibiotics & Sensitive & Semi-sensitive & Resistant \\
\hline Cephalothin (CF) & $34(59.6 \%)$ & $8(14 \%)$ & $15(26.4 \%)$ \\
Erythromycin (E) & $34(59.6 \%)$ & $16(28.1 \%)$ & $7(12.3 \%)$ \\
Tobramycin (T) & $14(24.6 \%)$ & $6(10.4 \%)$ & $37(64.9 \%)$ \\
Tetracycline (Te) & $21(36.8 \%)$ & $8(14 \%)$ & $28(49.1 \%)$ \\
Ampicillin (Am) & $0(0 \%)$ & $11(19.3 \%)$ & $46(80.7 \%)$ \\
Amoxicillin (Amx) & $6(10.5 \%)$ & $1(1.8 \%)$ & $50(87.7 \%)$ \\
Co-trimoxazole & $4(7 \%)$ & $1(1.8 \%)$ & $52(91.2 \%)$ \\
(S\&T) & & & \\
Vancomycin (Va) & $51(89.5 \%)$ & $4(7 \%)$ & $2(3.5 \%)$ \\
Cloxacillin (Cx) & $9(15.8 \%)$ & $3(5.3 \%)$ & $45(78.9 \%)$ \\
Gentamicin (Gm) & $14(24.6 \%)$ & $3(5.3 \%)$ & $40(70.2 \%)$ \\
Kanamycin (K) & $7(12.3 \%)$ & $8(14.5 \%)$ & $42(73.7 \%)$ \\
Penicillin (P) & $0(0 \%)$ & $0(0 \%)$ & $57(100 \%)$ \\
\hline
\end{tabular}

\section{DISCUSSION}

Group A beta-hemolytic streptococcal pharyngitis is one of the most common bacterial diseases in human being. Treatment and prevention of dangerous complications in this disease is of great importance. Healthy carriers of group A beta-hemolytic streptococcus are sources for bacterial dissemination and are able to communicate the disease and even lead to severe epidemics. According to different studies group A beta-hemolytic streptococcus is more seen in children's pharynx comparing to that of adults.

In this study, carrier state prevalence of group A beta-hemolytic streptococcus was $28.5 \%$ among samples. In other studies it has been reported between $6 \%$ and $35.4 \%{ }^{[3.14-18]}$ which is compatible with our achievement. Another study by Begovae and coworkers in Croutia showed that the maximum proportion of group A beta-hemolytic streptococcus carrier state was seen among 6-14 year old children and by the proportion of $11.7 \%^{[19]}$.

Performing antibiogram test on streptococci isolated from carriers showed that these bacteria were mostly sensitive to vancomycin,erythromycin and and cephalothin respectively, which is compatible with the study done in Kerman in 1995 (1).Performing an analysis on 19 studies, pechechero ME and coworkers claimed that oral cephalosporins had significantly higher cure rate comparing to penicillin(7). In a study accomplished by Nevaceeth and coworkers in India in 2001, all samples resulting from pharyngeal culture of group A beta-hemolytic streptococcus carrier children were sensitive to penicillin, erythromycin and cephazolin ${ }^{[17]}$ while in our study all of them were resistant to penicillin and sensitive to erythromycin and cephazolin which could be explained by incomplete and unnecessary treatment by penicillin in our community.

Relative resistance to ampicillin and amoxicillin was also seen in this study. Nowadays penicillin is still the first choice in treating group A beta-hemolytic streptococcal pharyngitis.

According to this study, practitioners' knowledge improvement about increased bacterial resistance to penicillin seems to be very important. Proper antibiotic prescription can prevent increasing of healthy carrier state. Of course because of the increasing trend of resistance to penicillin, several researches are being performed to find a suitable alternative.

Therefore, regarding the high prevalence of group A beta-hemolytic streptococcus carrier state among 1115 year-old children and according to increased resistance to commonly used drugs, more extended and comprehensive researches involving a broader age range, seems to be needed. 


\section{REFERENCES}

1. Hashemkhani, M., 1995. Isolation of group A beta hemolytic streptococcus in 150 children with sore throat and antibiogram test. Thesis in School of Pharmacy. Kerman medical University, pp: 48.

2. Kell, S.B. and L. Dick, 2000. Severe invasive group A beta-hemolytic streptococcus infection complicating pharyngitis: A case report on discussion. J. Okla State. Med. Assoc., 93: 25-8.

3. Gouthreir, M., 1996. Severe streptococcus betahemolytic group A infections in children. Arch. Pediatr., 3 (supp): 337s-8s.

4. Krobber, M.S., 1985. Streptococcal pharyngitis JAMA, 253: 1271-4.

5. Denny, F.W., 1950. Prevention of rheumatic fever. JAMA, pp: 151-3.

6. Wannamaker, L.W. and F.W. Denny, 1951. Prophylaxis of acute rheumatic fever. Am. J. Med., 10: 673-90.

7. Pechechero, M.E., J.R. Casey, T. Mayes and et al., 2000. Penicillin failure in streptococcal tonsillopharyngitis causes and remedies. Pediatr. Infect. Dis. J., 19: 917-23.

8. Brink, W.R. and F.W. Denny, 1951. Effect of Penicillin and Avermycin on natural course of streptococcal pharyngitis. Am. J. Med., pp: 103108.

9. Henry, J.B., 2001. Clinical Diagnosis and Management By Laboratory Methods. 20th Edn., Saunders Co., Philadelphia, pp: 1093-6.

10. Odimara, S., M.W. Luc-Louis, C.P. AntonioCarlos and N.P. Shirleyshizue, 2003. Detection of group A beta-hemolytic streptococcus employing three different detection methods: Culture, rapid antigen detecting test, and molecular assay. Braz. J. Infec. Dis., 7: 5.
11. Harods, C.S., 1990. Common Diagnosis Tests. 2nd Edn., A.C.P. Publication Co., USA, pp: 164-7.

12. Redetsky, M. and R.C. Wheeler, 1985. Comparative evaluation of kits for rapid diagnosis of group A streptococcus disease. Pediatr. Infec. Dis., 4: 274-81.

13. Centor, R.M. and G.E. Rvoff, 1987. Sore throat: Streptococcal or not? Pediatr. Care, 21: 28-63.

14. Betriv, C., J. Romario, A. Sanchez and et al., 1994. Carrier state of group A,B,C beta-hemolytic streptococcus. Enferm. Infec. Microbiol. Clin., 12: 285-8.

15. Gonzales-Lama, Z., J.J. Gonzalez and M.J. Lupiola-Tjedor, 2000. Carrier of group A,B,C betahemolytic streptococcus among school children in Las-Palmas. Enferm. Infec. Microbiol. Clin., 18: 271-3.

16. Gupta, R., K. Parkash, A.K. Kapoor, 1992. Subclinical group A beta-hemolytic streptococcus throat infection in school children. Indian Pediatr., 24: $149-60$.

17. Navaneeth, B.V., N. Ray, S. Chawola and et al., 2001. Prevalence of beta-hemolytic streptococcus carrier rate among school children in Salam. Indian J. Pediatr., 68: 985-6.

18. Stomberg, A., A. Schwan and O. Cars, 1998. Throats carrier rate of beta-hemolytic streptococcus among healthy adult and children. San. J. Infec. Dis., 20: 411-20.

19. Begovac, J., 1990. Asymptomatic Pharyngeal Carriage of Beta-hemolytic Streptococcus in Croatia. Principle and Practice of Infectious Disease. 3rd Edn., Churchil-Livingston Ltd. Philadelphia, pp: 1523. 